\title{
Energy Efficiency, Policy and GTFP
}

\author{
Fangqing $\mathrm{Yi}^{1,{ }^{*}}$, Zenglian Zhang $^{2}$ \\ 130 Xueyuan Road, Haidian District, Beijing, China \\ 230 Xueyuan Road, Haidian District, Beijing, China
}

\begin{abstract}
The environmental and resource constraints on economic growth are increasingly evident. China urgently needs to reshape its economic growth momentum. The increase in green total factor productivity is particularly necessary for the growth of the quantity and quality of the economy. This paper selects the provincial panel data of 30 provinces in China from 2001 to 2015, and establishes a panel exchangeable errors model to analyze the impact of eight indicators on green total factor productivity (GTFP) and verifies its effectiveness. Empirical analysis shows that inter-provincial government competition, environmental regulation, energy consumption, and capital stock have a significant impact on green total factor productivity. The influence of foreign direct investment, industrial structure, and industrialization level on the total factor productivity of green is not significant. Therefore, the government should adopt suitable, flexible and diverse environmental regulation policies, promote energy-saving emission reduction and technology innovations through policies such as taxes and subsidies, strengthen the linkage mechanism between industrial structure upgrading and energy efficiency, to increase green total factor productivity.
\end{abstract}

\section{Literature review}

Global economic development is increasingly constrained by prominent environmental and resource issues. It is not feasible to simply consider economic growth while ignoring the impact of resource and environment on the quality of economic growth. Experts and scholars in various countries have to introduce nontarget output when they study factor output. Other factors, such as environmental regulation, energy consumption, and energy efficiency, have led to the concept of "green total factor productivity" (GTFP) based on the original total factor productivity. Hu Xiaozhen[1] measures the impact of China's green Malmquist index, green technology efficiency, and green technology progress rate on the regional economic growth gap and its time evolution trend. Yin Baoqing [2] used the SBM model to measure the green total factor productivity of 27 manufacturing industries in China from 2002 to 2010 and examined industry differences in environmental regulation affecting total green factor productivity.Chen Chaofan[3] studied the influencing factors of industrial green total factor productivity through the SYS-GMM dynamic panel model. Li Bin [4] empirically tests the effects of fiscal decentralization, FDI, and their interaction items on green total factor productivity and decomposition items using the dynamic GMM method. Tan Zheng[5] used panel and dynamic space panel model method to compare and analyze the impact mechanism of green total factor productivity, green "soft technology" and green "hard technology".Liu Yongshi[6] uses the Malmquist index method of data envelopment analysis to consider the impact of industrial structure upgrading, energy efficiency, and their interactions on green total factor productivity. When researching green total factor productivity, domestic and foreign scholars usually target a particular industry or have too few analytical indicators. Therefore, the conclusions obtained are only applicable to the areas that they are based on and they have certain limitations when extrapolating. At present, there are few studies on the comprehensive mechanism of key indicators from the process of macroeconomic operations.

\section{Significance of study}

Figures and tables, as originals of good quality and well contrasted, are to be in their final form, ready for reproduction, pasted in the appropriate place in the text. Try to ensure that the size of the text in your figures is approximately the same size as the main text (10 point). Try to ensure that lines are no thinner than 0.25 point. The improvement of green total factor productivity under constraints of the environment and resources is an important indicator of a country's economic development quality, energy efficiency and technological innovation level. Under the guidance of a series of policies, the Chinese economy is changing from "extensive" to "intensive". China urgently needs to take supply-side structural reform as the main line and innovate to reshape the economic growth momentum. This is the core of green total factor productivity.

In the process of macroeconomic operations, environmental regulation, foreign investment, interprovincial government competition, industrial structure,

\footnotetext{
* Corresponding author: Fangqing Yi: yifangqingi@163.com
} 
etc. may affect a province's green total factor productivity. And provincial government's economic policies also affect the province's economic development model to a certain extent. Therefore, there is a big difference in the provincial total green factor productivity. This paper explores the key factors affecting GTFP and their impact mechanisms through the inter-provincial and time trends of various economic indicators, so as to provide suggestions for China's economic development on policy and factor utilization efficiency.

\section{Empirical analysis}

\subsection{Variable selection}

This paper selects the provincial panel data of Beijing, Tianjin, and a total of 30 provinces for analysis.In the empirical study of this paper, the data are from the China Statistical Yearbook 2001-2016, the China Industrial Economic Information Network, and the official website of the National Bureau of Statistics. Individual missing data are complemented by linear interpolation.

\subsection{Explanation to Introduced variables}

- Gtfp: Explained variables. This indicator represents Green Total Factor Productivity (GTFP) and Decomposition Items (GEC, GTP). Since the green total factor productivity measured by the ML index and the decomposition item are the ring growth index, in order to obtain the corresponding absolute value,this paper assumes that the total green factor productivity in 2003 is 1 , and the GTFP, GEC, and GTP ML indices are multiplied. That is, the GTFP in 2004 is the GTFP in 2003 multiplied by the ML index in 2004, the GTFP in 2005 is the GTFP of 2004 multiplied by the ML index of 2005, and so on, the GTFP of the corresponding year is empirically analyzed, and the operation of the decomposition item is the same.

- Gdp: This indicator is the annual per capita GDP of each province in 2001-2016.

- Tax: This indicator is used to measure interprovincial government competition. This paper draws on the study of Liu Jie[7] and uses the proportion of provincial tax revenues in GDP as an indicator of local government competitiveness. The higher the level of government competition, the lower the tax revenue to GDP ratio should be.

- Environment: This indicator is environmental regulation. This article draws on the study of $\mathrm{Li}$ Shenglan[8] and $\mathrm{Xu}$ Pengjie[9] and the ratio of revenue from sewage charges to industrial added value in each province is used as a measure.

- Fdi: This indicator is foreign direct investment. The foreign direct investment as a percentage of
GDP is used as a measure of the degree of openness of the investment.

- Upgrade: This indicator is the industrial structure, measured by the ratio of the added value of the secondary industry to the added value of the tertiary industry.

- Store: This indicator is the capital stock of each province.

- Industry: The indicator is the level of industrialization, measured by the ratio of gross industrial output value to GDP above the scale.

- Energy: This indicator is the energy consumption of each province in each year.

\subsection{Descriptive statistics of variables:}

Table 1. Descriptive statistics of variables.

\begin{tabular}{|l|l|l|l|l|l|}
\hline Variable & Obs & Mean & Std. Dev. & Min & Max \\
\hline province & 480 & 15.5 & 8.664472 & 1 & 30 \\
\hline year & 480 & 2008.5 & 4.614582 & 2001 & 2016 \\
\hline gtfp & 480 & 0.9114566 & 0.1482242 & 0.426905 & 1 \\
\hline tax & 480 & 0.0709374 & 0.0289885 & 0.0300303 & 0.1996512 \\
\hline environment & 480 & 50.92494 & 90.0084 & 1.298795 & 1002.98 \\
\hline fdi & 480 & 36.60623 & 29.87236 & 0.5830926 & 176.9565 \\
\hline upgrade & 480 & 0.9816794 & 0.4834943 & 0.4970531 & 4.165265 \\
\hline gdp & 480 & 3.034498 & 2.27431 & 0.2983074 & 11.81276 \\
\hline industry & 480 & 1.168065 & 0.431479 & 0.3612066 & 2.349565 \\
\hline store & 480 & 13602.84 & 9737.557 & 1910.8 & 43924.44 \\
\hline energy & 480 & 11143.46 & 7766.707 & 520 & 39191.67 \\
\hline
\end{tabular}

\subsection{Model selection and construction}

This paper uses the "exchangeable errors model" to analyze the influence mechanism of each index on GTFP. $y_{i t}=x_{i t}^{\prime} \beta+z_{i}^{\prime} \delta+u_{i}+\varepsilon_{i t}(i=1, \ldots \ldots, n ; t=1, \ldots \ldots, T)$

Among them, $\mathbf{Z}_{i}$ is an individual characteristic that does not change with time (time invariant, $\mathrm{z}_{i t}=z_{i}, \forall t$ ); $\mathrm{X}_{i t}$ can change with the individual and time (timevarying); the disturbance term is composed of two parts of AB, called "complex disturbance item".

For the above regression equation, the random effects model assumptions $u_{i}$ and the explanatory variables $\left\{\mathrm{x}_{i t}, z_{i}\right\}$ are not related, so the OLS is consistent. However, OLS is not the most efficient because the disturbance term consists of $\left(u_{i}+\varepsilon_{i t}\right)$ and is not a spherical disturbance term.

\subsubsection{Conduct Hausman test}


Table 2. Result of Hausman test.

\begin{tabular}{|c|c|c|c|c|}
\hline & (b) & (B) & (b-B) & $\begin{array}{l}\text { sqrt(diag(V } \\
\text { b-V } \quad \text { B)) }\end{array}$ \\
\hline & $F E$ & $R E$ & Difference & S.E. \\
\hline stax & -0.2386075 & & -0.0014149 & 0.0046435 \\
\hline sen & -0.0585533 & & -0.0018743 & 0.0014115 \\
\hline sup & -0.0906868 & & 0.0142154 & 0.0106574 \\
\hline sgdp & .0502175 & .027636 & 0.0225815 & 0.0102525 \\
\hline $\sin$ & -.0012966 & .00158 & -0.0028766 & 0.0057257 \\
\hline senergy & -0.2196269 & & 0.0575957 & 0.0284127 \\
\hline sstore & -.013571 & .3155279 & $\begin{array}{l}-0.3290989 \\
\end{array}$ & 0.1441733 \\
\hline cons & $-1.054 \mathrm{E}-08$ & & $3.99 \mathrm{E}-10$ & \\
\hline \multicolumn{5}{|c|}{$\begin{array}{l}\text { Test: Ho: difference in coefficients not systematic } \\
\operatorname{chi2}(8)=(\mathrm{b}-\mathrm{B})^{\prime}\left[\left(\mathrm{V}_{-} \mathrm{b}-\mathrm{V} \_\mathrm{B}\right)^{\wedge}(-1)\right](\mathrm{b}-\mathrm{B})=12.03\end{array}$} \\
\hline \multicolumn{5}{|c|}{ Prob $>$ chi2 $=0.1497$} \\
\hline
\end{tabular}

Accept the original hypothesis " $H_{0}: u_{i}$ is not related to $x_{i t}$ and $z_{i}$ " and think that the random effects model should be used instead of the fixed effects model.

\subsubsection{LM test for individual-specific effects}

Breusch and Pagan Lagrangian multiplier test for random effects:

Table 3. Estimated results.

\begin{tabular}{|c|c|c|}
\hline & Var & $\mathrm{sd}=\operatorname{sqrt}($ Var $)$ \\
\hline sgtfp & 1 & 1 \\
\hline $\mathrm{e}$ & .0657793 & .2564748 \\
\hline $\mathrm{u}$ & .7430185 & .8619852 \\
\hline \multicolumn{3}{|c|}{$\operatorname{sgtfp}[$ province, $\mathrm{t}]=\mathrm{Xb}+\mathrm{u}[$ province $]+\mathrm{e}[$ province, $\mathrm{t}]$} \\
\hline \multirow{2}{*}{\multicolumn{3}{|c|}{$\begin{array}{c}\text { Test: } \quad \operatorname{Var}(\mathrm{u})=0 \\
\text { chibar2(01) }=2677.67\end{array}$}} \\
\hline & & \\
\hline \multicolumn{3}{|c|}{ Prob $>$ chibar $2=0.0000$} \\
\hline
\end{tabular}

\subsection{Maximum likelihood estimation of random effects model}

Table 4. Estimated results.

\begin{tabular}{|l|l|l|l|l|l|}
\hline sgtfp & Coef. & Std.Err & $\mathrm{z}$ & $\mathrm{P}>|\mathrm{z}|$ & {$[95 \%$ Conf. } \\
\hline stax & -.1185978 & .0371223 & -3.19 & 0.001 & -.1913562 \\
\hline sen & -.0283602 & .0135162 & -2.10 & 0.036 & -.0548515 \\
\hline sup & -.0522257 & .0410967 & -1.27 & 0.204 & -.1327738 \\
\hline sgdp & .0282639 & .034805 & 0.81 & 0.417 & -.0399525 \\
\hline sin & .0015159 & .0378466 & 0.04 & 0.968 & -.0726621 \\
\hline senergy & -.1371561 & .0569502 & -2.41 & 0.016 & -.2487765 \\
\hline sstore & .3066887 & .1450313 & 2.11 & 0.034 & .0224325 \\
\hline cons & $-5.466-09$ & .1616213 & -0.00 & 1.000 & -.3167719 \\
\hline /sigma_u & .8829332 & .1201148 & & & .6762851 \\
\hline /sigma_e & .2552476 & .0085362 & & & .2390534 \\
\hline rho & .9228725 & .0200608 & \multicolumn{5}{|c|}{ Prob >= chibar2=0.000 } \\
\hline \multicolumn{7}{|c|}{ LR test of sigma_u=0: chbar } \\
\hline
\end{tabular}

\section{Results and analysis}

Overall, inter-provincial government competition, environmental regulation, energy consumption, and capital stock have a significant impact on green total factor productivity. However, the influence of industrial structure and industrialization level on the total factor productivity of green is not significant.

First, GTFP has obvious regional cluster characteristics in geographical distribution. GTFP in the southeastern coastal provinces remained at a relatively high level, while some midwestern provinces exhibited lower GTFP levels. However, GTFP does not correspond to the level of economic development in the provinces. Provinces with lower GDP do not strictly exhibit lower GTFP.

Second, the government usually conducts interprovincial competition through taxation. What we are familiar with is to attract investment and build factories through taxation policies and tax breaks for new energy companies. The lower the ratio of tax revenue to GDP, the higher the degree of competition among interprovincial governments. Judging from the above empirical analysis results, the taxation policy makes a lot of sense.

Third, the degree of environmental regulation has a positive effect on the improvement of green total factor productivity. The most important goal of the enterprise is undoubtedly the pursuit of profit maximization. The government's increased pollution restrictions on companies, especially industrial companies, will force companies to use emissions as an important indicator of their profits in the production process. Under the government's environmental regulations, enterprises will voluntarily reduce their pollution problems through increasing energy efficiency and technological innovation, which will increase the industry's green total factor productivity.

Fourth, capital stock has a significant positive effect on the improvement of green total factor productivity. Capital stock does not mean simply increasing factor input to increase output and promote economic growth. The most important significance of the capital stock is to support technological innovation, promote the adjustment and optimization of industrial structure, and increase the efficiency of factor utilization. On the other hand, the capital stock provides the basis for promoting supply-side structural reforms and innovations for economic growth.

Fifth, the level of industrialization and industrial structure have no significant effect on green total factor productivity, and the direction of influence is not fixed. Both the "U-shaped curve" and the "Environment Kuznets Curve" can confirm this conclusion from the side. There is no strict direction correspondence between the level of economic development and green total factor productivity.

\section{Conclusions and suggestions}

Based on the geographical cluster characteristics of GTFP, government can select pilot provinces in the course of economic policy control, and use the 
demonstration effect to drive neighboring provinces to jointly increase green total factor productivity so as to achieve regional expansion (spillover effect) of energy efficiency and technological innovation.

The development of environmental regulations as a powerful policy means to increase green total factor productivity must be strictly implemented. The government should adopt flexible, flexible and diverse environmental regulation policies and fully exert the positive effects of GTFP on the synergies with vertical specialization. Pay attention to the role of environmental regulation in promoting technological innovation and improving energy efficiency so that the economy can achieve quality growth. At the same time, the central government is suggested to give greater weight to the "green economy" indicator for the evaluation of the performance of local officials.

The government should formulate a specific path for optimizing and upgrading the industrial structure based on the capital stock and energy consumption. Through taxation subsidies and other policies to promote energy saving and emission reduction technology, strengthen the linkage mechanism of industrial structure upgrading and energy efficiency, and enhance the green total factor productivity.

\section{Future research}

In the subsequent studies, the regional linkage of energy efficiency and technological innovation will be included in the measurement indicators, and the effectiveness evaluation system of relevant policies on GTFP will be studied.

\section{References}

1. Hu Xiaozhen, Yang Long. Regional differences in green total factor productivity growth and convergence analysis in China [J]. Finance and Economics Research, 37(2011): 123-134.

2. Yin Baoqing. Environmental Regulation and Green Total Factor Productivity in China's Manufacturing Industry: An Empirical Study Based on International Vertical Specialization[J]. China Population, Resources and Environment, 22(2012): 60-66.

3. Chen Chaofan. China's Industrial Green Total Factor Productivity and Its Influencing Factors: An Empirical Study Based on ML Productivity Index and Dynamic Panel Model [J]. Statistical Research, 33(2016):53-62.

4. LI Bin, GENG Yuan, LI Qian. Fiscal Decentralization, FDI and Green Total Factor Productivity: An Empirical Test Based on Panel Data Dynamic GMM Method [J]. International Trade Issues, 07(2016): 119-129.

5. TAN Zheng,WANG Xueyi.Empirical study of interprovincial spatial learning effects of green total factor productivity[J].China Polity, Resources and Environment, 26(2016):17-24.
6. Liu Yingshi, Tian Yinhua, Luo Ying. Industrial structure upgrade, energy efficiency and green total factor productivity $[\mathrm{J}]$. Finance and Economics Theory and Practice, 39 (2018): 118-126.

7. Liu Jie, Li Wen. China's Environmental Pollution and Local Government Tax Competition: An Analysis Based on Spatial Panel Data Model [J]. China Population, Resources and Environment, 23(2013): 81-88.

8. Li Shenglan, Chu Shanbing, Shen Chen. Local government competition, environmental regulation and regional eco-efficiency [J]. World Economy, 37(2014): 88-110.

9. Xu Pengjie. Environmental Regulation, Green Technology Efficiency and Pollution-Intensive Industry Transfer[J]. Finance and Economics Review, 02(2018): 11-18.

10. Han Jing, Zhang Xin. Is Green Growth a Major Factor Affecting Officials' Promotion?_-An Empirical Study Based on Provincial Panel Data from 2003 to 2014 [J]. Comparative Economic and Social Systems, 05(2016):12- 24.

11. Yu Ying, Zhang Jie. Carbon emissions, green total factor productivity and economic growth [J]. Quantitative Economics and Technology Economics Research, 33(2016):47-63.

12. Wang Bing, Liu Guangtian. Energy Saving and Emission Reduction and China's Green Economy Growth: A Perspective of Total Factor Productivity $[\mathrm{J}]$. China Industrial Economy, 05(2015):57-69.

13. Wang Feng, Jie Jin. Research on the Growth Rate of Green Total Factor Productivity in China's Provinces[J]. Chinese Journal of Population Science, 02(2015): 53-62+127.

14. [16] Song Changqing, Liu Congfen, Wang Xiaojun. Measurement and Decomposition of Green Total Factor Productivity in China: 1985-2010[J]. Journal of Northwest A\&F University (Social Science Edition), 14(2014): 120-127.

15. Yin Baoqing. Environmental regulation and technological innovation [D]. Zhejiang University, 2013.

16. Wang Keliang, Yang Li, Cheng Yunhe. Factor utilization, energy saving and emission reduction and regional green total factor productivity growth[J]. Economic Management, 34(2012):30-43. 